\title{
Carnets
}

Revue électronique d'études françaises de l'APEF

Première Série - 3| 2011

$\mathrm{L}^{\prime}($ In)vraisemblable

\section{Manuel de Figueiredo, atento leitor de Aristóteles e Corneille ou de como o desejo de verdade pode naturalmente conduzir ao inverosímil}

\section{Maria Luísa Malato Borralho}

\section{(2) OpenEdition \\ Journals \\ Edição electrónica \\ URL: http://journals.openedition.org/carnets/5908 \\ DOI: $10.4000 /$ carnets.5908 \\ ISSN: 1646-7698 \\ Editora \\ APEF}

\section{Edição impressa}

Data de publição: 2 Janeiro 2011

Paginação: 49-69

\section{Refêrencia eletrónica}

Maria Luísa Malato Borralho, « Manuel de Figueiredo, atento leitor de Aristóteles e Corneille ou de como o desejo de verdade pode naturalmente conduzir ao inverosímil », Carnets [Online], Première Série - 3 | 2011, posto online no dia 18 junho 2018, consultado o 21 abril 2019. URL : http:// journals.openedition.org/carnets/5908; DOI : 10.4000/carnets.5908

\section{(c) (1) (8)}

Carnets est mis à disposition selon les termes de la licence Creative Commons - Atribution - Pas d'utilisation commerciale 4.0 International. 


\title{
MANUEL DE FIGUEIREDO, ATENTO LEITOR DE ARISTÓTELES E CORNEILLE OU DE COMO O DESEJO DE VERDADE PODE NATURALMENTE CONDUZIR AO INVEROSÍMIL
}

\author{
MARIA LUÍSA MALATO BORRALHO \\ Universidade do Porto/ ILC-ML ${ }^{1}$ \\ mlmalato@gmail.com
}

\begin{abstract}
Resumo
"Eu quero escrever dramas úteis e verosímeis", eis o repetido fito de Manuel de Figueiredo, ao longo dos seus quase 14 volumes de Teatro e vinte anos de leitura dos Antigos e Modernos (1756?-1777). Mas quantas tensões não esconde esta uniformidade? Mesmo depois de Francisco Coelho de Figueiredo Ihe ter editado postumamente a obra, M. de Figueiredo raramente foi lido e estudado. Das suas peças, só uma chegou aos palcos (e foi logo retirada de cena). Concebemo-lo como "académico" e imitador servil do classicismo, greco-latino ou francês. Mas Aristóteles e Corneille foram talvez a sua mais remota alavanca crítica, isto é, os autores que mais precocemente incentivaram nele a ponderação das relações paradoxais entre a Inverosimilhança e a Verdade, a Arte e a Realidade, a Literatura e a Dramaturgia.
\end{abstract}

\begin{abstract}
"I want to write useful and verisimilar plays", that was the first and the last intention of Manuel de Figueiredo, successively repeated during twenty years of activity and fourteen volumes of plays and texts about theatre, reading the Ancients and the Moderns (1756?-1777). But how many contradictions and hesitations hidden by this constant intention! We must considerer that Figueiredo was not a very well-known writer (even if Francisco Coelho de Figueiredo managed to publish his work after his death). His plays (with one calamitous exception) were never put on stage. He is often considered an academic writer, an imitator of Aristotle and the French Classicism. And yet to him, Aristotle and Corneille were not only a conventional source of knowledge, but the lever of a precocious way of thinking the relation between Inverisimilitude and Truth, Art and Reality, Literature and Dramaturgy.
\end{abstract}

Palavras-chave: Inverosimilhança, Imitação, Manuel de Figueiredo, Teatro, Dramaturgia Keywords: Inverisimilitude, Imitation, Manuel de Figueiredo, Theatre, Dramaturgy

\footnotetext{
'Artigo elaborado no âmbito do Projecto Interidentidades", do Instituto de Literatura Comparada Margarida Losa (Faculdade de Letras, Univ. do Porto), Unidade I\&D financiada pela FCT, e integrada no Programa Operacional Ciência e Inovação 2010 (POCl 2010), do Quadro Comunitário de Apoio III (POCl 2010-SFA-18-500).
} 
Agora porém he que eu conheço o labyrintho em que me metti.

Eu queria escrever dramas úteis e verosímeis.

(Manuel de Figueiredo, Theatro, I, Prologo)

A única peça de Manuel de Figueiredo (1725-1801) de cuja representação temos notícia foi Perigos da Educação, que subiu aos palcos do Bairro Alto, na noite de 8 de Maio de 1774. Tenebrosa noite foi para o autor porque a atitude do público lhe valeu ter sido logo retirada dos cartazes: saiu o público para a rua rindo, e repetindo dela o que mais tinha gostado, o desabafo de uma das personagens: O que he o Mundo!" (Figueiredo, 1804-1815: I, s.p., Prol. "O Drammatico Affinado").

Havia na frase qualquer coisa de óbvio e tautológico, que tudo ou nada queria dizer, mas consubstanciava a ilegibilidade e a inverosimilhança daquilo a que tinham assistido. $\mathrm{E}$ não deixava de ser paradoxal que essa crítica implícita de ilegibilidade e inverosimilhança, o público a fosse buscar à deixa de uma personagem, que também ela se admirava com as fantásticas contradições da sociedade.

"O que he o Mundo!", comentava Manuel de Figueiredo a esse e a outros propósitos (ibidem e ibid: V, 220). E essa frase sucessivamente repetida pela personagem, pelo público que comenta a personagem e pelo autor que comenta o público, nos parece reproduzir exemplarmente uma inverosimilhança da inverosimilhança que causa ainda hoje em nós, leitores distanciados do teatro de Manuel de Figueiredo, um idêntico efeito especular e espectacular. Para todos - da personagem aos espectadores, dos espectadores ao autor, do autor aos seus leitores - o Mundo é, afinal, um lugar estranho, onde o que se acaba por obter é a mais perfeita negação do que se busca. Como se, no Mundo, a inverosimilhança fosse o resultado da busca desesperada de verdade e as ideias, levadas ao seu limite, se tornassem afinal os argumentos mais incisivos contra as ideias que os geraram. Como se, no Mundo, qualquer forma contivesse já a sua incipiente deformação.

Passando as portas do teatro ou fechando o livro, sempre se regressa a outro palco, a que chamamos erradamente nosso, esperando que juntos façam sentido. Ainda que seja difícil percorrer esse sentido. Porque o Mundo do Teatro se opõe muitas vezes ao Teatro do Mundo, sendo o primeiro falso e fantasista e o segundo verdadeiro e rotineiro. O Autor e o Actor pedem essa licença poética de fazer de conta, habitando um mundo que o não o é. $E$ o Leitor e o Espectador Iha dão, dirigindo o olhar e a imaginação para esse mundo. E todos dependem dessa liberdade que atira a Arte para uma dimensão virtual, tão intensa e gasosa quanto uma Second Life. A Carta aos Pisões começa precisamente com a evocação desse pacto de verosimilhança, feito, todavia, de liberdade e concessão: 
- Suponhamos que um pintor entendesse de ligar a uma cabeça humana um pescoço de cavalo, ajuntar membros de toda a procedência e cobri-los de penas variegadas, de sorte que a figura, de mulher formosa em cima, acabasse num hediondo peixe preto; entrados para ver o quadro, meus amigos, vocês conteriam o riso? Creiam-me Pisões, bem parecido com um quadro assim seria um livro onde se fantasiassem formas sem consistência, quais sonhos de enfermo, de maneira que o pé e a cabeça não se combinassem num ser uno.

- A pintores e poetas sempre assistiu a justa liberdade de ousar seja o que for...

- Bem o sei; essa licença nós a pedimos e damos mutuamente...

E só depois o texto de Horácio restringe essa liberdade e reforça uma vez mais os seus limites:

Não, porém, a [liberdade] de reunir animais mansos com feras, emparelhar cobras com passarinhos, cordeiros com tigres. (Horácio, 1985: 55)

"O que he o Mundo!". Ou "O que he o Mundo?". Da personagem ao espectador, do autor ao leitor, talvez, na produção como na crítica literária, tudo se possa afinal resumir à exclamação inicial, aquela que se confunde com uma pergunta, o espanto que convive com o incómodo. A peça de Manuel de Figueiredo, escrita em 1773, mais claramente ainda do que as suas produções para a Arcádia Lusitana, nos anos de 1757 e 1758, nasce aliás, segundo o próprio autor, desse espanto e desse incómodo de viver num mundo limitado e feito de "lugares-comuns", que são, retoricamente, os argumentos que podem ser evocados e compreendidos por todos, independentemente da sua formação específica: o espanto e o incómodo pelos rituais, clichés, gestos e palavras que perderam o sentido por se terem muitas vezes repetido. Desligado já da breve instituição arcádica, no refúgio da toca doméstica, escreve já por enfado de tudo o que é fútil ao longo de doze anos em que os teatros foram encerrados em Portugal. E também talvez escreva por desenfado de si: "as noites de Pancas, de Pinheiro, de Salvaterra, depois de doze anos de disputas ao wisth, já se não podiam aturar" (Figueiredo, 1804-1810: II, 212). Escreve porque tem de escrever, fisionomicamente, por impulso, por necessidade, como se coça uma pessoa que tem comichão: "a poesia dramática trabalhava-me, e trabalhava-me tanto que já nem podia ir aos teatros" (Figueiredo, 1804-1810: II, 211). No século XVIII, como hoje, em todas as épocas afinal, se o estranhamento é (a par do reconhecimento) um dos motores do sentimento retórico, então a inverosimilhança se introduzirá na arte, quer em tudo o que se torna reconhecidamente real, quer no que é evidentemente irreal. $E$ o tédio do que é vulgar nos cansará das verdades comuns, demasiado comuns e rotineiras. "Il rêve d'échafauds en fumant son houka" (Baudelaire, 1979: 34). Antoine Compagnon referia as várias 
possibilidades de concordância com um colega que escandalizava os académicos atribuindo unicamente à literatura o poder de matar o Tempo, afinal a evocação daquele baudelaireano matar o Tempo "qui a la vie si dure, et accélérer la Vie qui coule si lentement" (Compagnon, 2010: 39-40). Ainda para o teatro moderno, dirá Peter Brook².

O grande princípio que me orienta no trabalho e no qual sempre presto a maior atenção, é o tédio. Como um demónio astuto, o tédio pode aparecer no teatro a qualquer momento. Sempre à espreita e voraz, costuma atacar ao menos pretexto, infiltrando-se sorrateiramente numa acção, num gesto ou numa frase. (Brook, 2008: 31)

O que os espectadores de Manuel de Figueiredo poderiam estranhar era afinal um Mundo do Teatro que Ihes parecia tão verdadeiro e tão rotineiro que facilmente o desprezavam. Reagiam, de certa maneira, à traição que é um teatro que se pode confundir com a vida comum, a vida que no fundo desprezavam. lam ao teatro por deleite, por desejo de fantasia, pela diferença que o Teatro tinha da Vida. O que eles viam e ouviam nas comédias dos palcos de Lisboa preenchia essa necessidade básica de ser surpreendido. $A$ Vida sabiam eles o que era (ou pensavam saber): não iam ao Teatro ver a sua Vida, mas a Vida que não podiam ter. O próprio Manuel de Figueiredo, ainda quando critica o que vê nos palcos lisboetas, diz-se deles assíduo frequentador. A inverosimilhança é, desde logo para Manuel de Figueiredo, um factor de prazer tão grande quanto a verosimilhança. E por isso se diz fascinado, apesar de tudo, pelo inverosímil "romanesco" que encontra no teatro popular:

Nellas vejo a cada passo hum que naufragou em uma ilha deserta; outro que foi achado nas mantilhas em huma praia; outro que estava para casar com a irmã, que não conhecia; outro que se fingio marido de uma mulher, que tinha o esposo na América; outra dama caprichosa, que foi correr o mundo para vencer a inconstancia de hum homem, e outro que se namora de hum retrato a perder o juízo; e muito semelhantes idéas romanescas, ainda insupportaveis para sustentar huma novella. (Figueiredo, 1804-1810: I, 115-116) ${ }^{3}$

\footnotetext{
2 Do estranhamento enquanto conceito fulcral da Poética aristotélica à desautomatização do sentido associado ao texto literário pelo Formalismo russo, sempre nos surpreende "el descubriento que se ha llevadoa término en una obra de arte, se nos antoja ya distinto el mundo en que habíamos vivido sin abrir los ojos, y desde entonces, si el cuadro, el libro o el poema fueron realmente reveladores, nos parecerá el mondo más ancho, más rico y más inaprehensible. Desde que hemos gozado la primera revelación, no acertaremos a vivir como antes: presentiremos arcanos que no podemos descifrar ni apartar de la imaginación, y todas las cosas habrán cobrado algo así como un nimbo de incertidumbre que nos hace verlas de manera distinta (...)" (Aguado, 1942: 12).

3 Decorrendo desta tensão entre verosimilhança e inverosimilhança, ocorrem os problemas de dramaturgia e maquinaria levantados, desde sempre, pelas cenas de naufrágio e ilhas desertas, nomeadamente numa cenografia tendencialmente realista (cf. Brook, 2008: 90-94).
} 
"A verdade, e simplesmente a verdade, é a sublime arte, a rica veia e a lira de ouro com que os poetas devem entoar aquele harmonioso canto..." (Figueiredo, 1804-1815: I, "Dedicatória"). Guiá-lo-ia portanto "simplesmente a verdade"! Mas podia ele, quando escreve estas palavras para os académicos da Arcádia Lusitana, em 1758, ter definido com precisão de que verdade falava ele, desde logo? A verdade do Mito ou a verdade da História? A das coisas tal como são, tal como parecem ser, ou tal como deviam ser? Ou, retomando a questão prévia: a realidade que nos entedia ou aquela que nos surpreende? As últimas páginas da Poética de Aristóteles procuram responder-Ihes, listando um conjunto vasto de problemas críticos literários e retóricos, a que o texto incompleto (tal como é conhecido) não chega a dar resposta:

O poeta é imitador, como o pintor ou qualquer outro imaginário; por isso, a sua imitação incidirá num destes três objectos: coisas quais eram ou quais são, quais os outros dizem que são ou parecem, ou quais deveriam ser. Tais coisas, porém, ele as representa mediante uma elocução que compreende palavras estrangeiras e metáforas, e que, além disso, comporta múltiplas alterações, que efectivamente consentimos ao poeta. Acresce, ainda, que não é igual o critério de correcção na poética e na política, e semelhantemente, o de qualquer outra arte, em confronto com a poesia. (Aristóteles, 1986: 143, 1460b)

Aristóteles, fiel que parece ser à diversidade resultante dos critérios da natureza e da necessidade, não nega a possível eficácia poética de nenhuma das opções. Até porque (pese embora, segundo Aristóteles, a maior importância da fábula sobre a representação) o Teatro "aristotélico" é um espaço de mimésis complexa, em que os meios, os objectos e os modos da Poesia se misturam com os da Música e com os da Dança. Castelvetro e os preceptistas italianos tinham lido nele a recomendação da unidade de tempo: "a tragédia procura, o mais que é possível, caber dentro de um período de sol, ou pouco excedê-lo" (Aristóteles, 1986: 109, 1449b). Mas o que é que dela deve "caber dentro de um período de sol"? O tempo da representação, ou o tempo da intriga? E o que é um "período de sol"? Doze horas, vinte e quatro horas, como preconizavam os mais rígidos? Ou excedendo-o trinta, ou trinta e seis, como se permitia Corneille? Manuel de Figueiredo, perante os académicos da Arcádia Lusitana, opta pela solução que é aparentemente a mais artificial de todas as propostas: o tempo de representação. Três horas devem ser, se três horas "é o mais que pode durar a representação" (Figueiredo, 1804-1810: I, 163). Doze seriam então, ou vinte e quatro, se por exagero ("liberdade") a representação durasse um dia. Solução inverosímil? Talvez. Mas inegavelmente a mais próxima de uma "verdade" no palco, 
confundindo-se o tempo da intriga, o tempo da representação do actor e o tempo do espectador que a ela assiste, ficando "a natureza sujeita à arte tão venturosamente que não os podemos distinguir" (ibid: I, 126).

Como qualquer mestre, Aristóteles deixa mais perguntas do que respostas. Como qualquer admirável Bíblia, a Poética tudo contém: da norma à sua excepção, até à excepção como norma. Em Aristóteles, se dá como preferível o impossível verosímil (adynata eikota) à possibilidade incrível (dynata apithana). A própria "impossibilidade" é desculpável se resultar mais impressionante:

O poeta representou impossíveis. É um erro - desculpável contudo, se atingiu a finalidade própria da poesia (...) e se, de tal maneira, resultou mais impressionante essa parte do poema, ou outra qualquer. (...) Além disso, quando no poeta se repreende uma falta contra a verdade, há talvez que responder como Sófocles: que representava ele os homens tais como devem ser, e Eurípedes, tais como são (...). (Aristóteles, 1986: 143, 1460b) ${ }^{4}$

A tensão estética e retórica, sempre necessária, entre a inverosimilhança do estranhamento e a verosimilhança do espectável, tanto se pode obter buscando a verdade do Mito como a verdade da História. Aristóteles, discípulo e contraditor de Platão, parece fazer da própria ideia de Belo um conceito em tensão que é simultaneamente universal, incipientemente ontológico, e sociológico, manifestamente fenomenológico. É sabido que, desde o século XVII, pelo menos, esse pendor sociológico do Belo, resultante da ponderação da variedade existente (le beau réuni), vai obnubilando a definição "ontológica" (le beau idéal).

A querela dos Antigos e dos Modernos, ao associar os Antigos a um "belo ideal" e os modernos a um "belo reunido ou ponderado", radicalizará posições e distorcerá o pensamento quer dos Antigos quer dos Modernos, como já se queixava La Bruyère Cochin ou Perrault (Joly, 2009: 393 ss.; Costa, 2004: 233-255). Considerado sob este aspecto, o da definição sociológica do Belo ao longo dos séculos XVII e XVIII, é muito interessante o diálogo entre Aristóteles e Figueiredo. Porque, ao contrário de Aristóteles, que proclamara a superioridade da Poesia (centrada na Verosimilhança e no Universal) quando comparada com a História (limitada à Verdade e ao Particular), Figueiredo exortava os árcades a valorizar a História. Carlos Brejo da Costa chama a atenção para a utilização que Manuel de Figueiredo (no Discurso que prefacia a tragédia As Irmãs, de 15 de Outubro de 1775) faz de

\footnotetext{
4 Curiosa esta observação de Aristóteles sobre Sócrates e Eurípedes. Convém não esquecer o distanciamente que possui em relação à obra de ambos: Aristóteles nasceu 86 anos depois de Sófocles e 96 anos depois de Eurípedes. Trata-se, pois, de uma observação que contém já um determinado peso canónico.
} 
uma citação de Diderot, criticando Horácio, por ele não ter incentivado os poetas a imitar os gostos e os costumes dos homens seus contemporâneos (Costa, 1962: 20). E não devemos esquecer as palavras de Figueiredo na Arcádia Lusitana, incentivando os Árcades a tornarem-se Historiadores, menorizando a funcionalidade social da Poesia:

Agora, Senhores, o que eu queria persuadir-vos era que escrevêsseis em prosa: temos mais Poetas que Historiadores; que estes sejão mais precisos à República do que aquelles, escuso mostrar-vo-lo; vedes o mundo cheio de Academias da História, não apontareis huma de Poesia que floresça. (Figueiredo, 1804-1810: II, 154, Discurso I) ${ }^{5}$

Poder-se-ia pensar, ao ler uma tragédia como $D$. Inês (já de 1774), que Manuel de Figueiredo estabelece para o Teatro o que Verney preconizara para a Poesia, na Carta Sétima: "um conceito que não é justo, nem fundado sobre a natureza das coisas, não pode ser belo, porque o fundamento de todo o conceito engenhoso é a verdade" (Verney, 1991: 128). Mas na averiguação sobre o que é "a natureza das coisas", há sobretudo necessidade, como já foi plenamente demonstrado por José Oliveira Barata, de realçar a emergência da História na Identidade, como estratégia incipiente de um século que desejava já inspirar uma reflexão alargada sobre o que vem a ser um teatro nacional (Barata, 2001: 68-69).

Manuel de Figueiredo é talvez o árcade que melhor representa esse esforço, e nos permite analisar os elementos de continuidade com o teatro de Garrett (Garrett, s. d.; 1622, "Carta a um amigo", Catão; e Barata, 2001: 114-121). Se alguma utilidade Manuel de Figueiredo teve para Garrett, não foi a de ser autor de uma poética, mas o questionador de muitas. Figueiredo lê, relê, pondera, diz e desdiz-se, muda de estratégia, e não nega nunca a complexidade do preceito aristotélico sobre a comparação da Poesia com a História. Mantendo a referência da autoridade clássica, legitimadora da ortodoxia e da heterodoxia, vai oscilando, consoante os anos e os géneros dramáticos, ciente de que a Poesia pode usar da verdade e do particular da História, tal como a História pode fundamentar a verosimilhança e o universal da Poesia. Ainda que Manuel de Figueiredo use da verdade histórica para colocar em cena uma $D$. Inês com preocupações domésticas sobre a hora de jantar e já com os filhos criados (tão longe daquela mítica Inês de Camões, "posta em sossego", com os meninos "tão mimosos,/ cuja orfandade como mãe temia"), é com a verdade do mito que justifica o enredo e a construção das personagens da ópera Diomedes,

\footnotetext{
5 Hume, nas Investigações sobre o Entendimento Humano, valorizara também o magma comum da História e da Poesia: o Real. No mesmo sentido, a literatura setecentista em geral, e o drama histórico em particular, se deixa seduzir pela intersecção entre a verdade histórica e a verdade mítica. O romance histórico do século XIX persistirá pois como um fenómeno de hibridismo e continuidade, nunca de ruptura, desde logo entre o que possam ser os "neoclássicos" e os "românticos".
} 
onde foi "tão pouco escrupuloso em averiguar a verdade". Dividido entre a "imitação icástica" mais próxima do Belo real (própria de um tempo e de um espaço literal/real) e uma "imitação fantástica" ligada ao Belo ideal (e elaborada a partir de uma estrutura espacio-temporal metafórica/ mítica), Figueiredo afirma que, quer as mais incisivas verdades, quer as mais eficazes mentiras, se compõem sempre (algo paradoxalmente) de uma estranha mistura de mentiras e verdades: "porque duro com duro não faz muro" (Figueiredo, 1804-1815: XII, 51, em "O avaro dissipador"). ${ }^{6}$

Não devemos talvez separar este interesse de Manuel de Figueiredo pela História daquele que ele manifesta também por Eurípedes (o tragediógrafo que, no dizer de Aristóteles, pintava os homens como eles são), nomeadamente nas peças que escreveu entre 1773 e 1777, durante a última fase da sua criação dramática, a nosso ver, a sua fase experimental e crítica mais interessante. Pois parece-nos que, ao traduzir Ifigénia em Aulide, de Eurípedes, em 1777, Figueiredo o faz ainda para "sofoclizar" Eurípedes, mas já insatisfeito com a estética de Sófocles, mais depurada e atemporal. Sófocles, significativamente, é um modelo que está mais presente na sua fase arcádica: não é por acaso que a peça que apresenta em 1757 à Arcádia Lusitana é Édipo. É sua finalidade apresentar então, face aos costumados excessos do teatro italiano, um drama a que se retiraram os traços de uma realidade passional e circunstancial: "vereis hum Drama sem amor, sem confidentes, sem Amas, sem solilloquios, sem à partes" (Figueiredo, 1804-1815: XIII, xvi, "À Arcadia"). Mas por ocasião da adaptação de Eurípedes, em 1777, diz o autor, pelo contrário, ter conservado muitas singelezas que parecem abater a grandeza do poema, mas ter tido de corrigir outras, pouco próprias do seu século. Porque admitindo ele muitas extravagâncias, mantém uma aversão quase pessoal a certas formas de inverosimilhança. Aquelas que coloquem em causa o tipo sociológico ou político, e comprometam a dignidade e grandeza de certos cargos ou funções:

Confundam-se os séculos, volte-se o mundo, e adoptem-se quantas extravagâncias se podem esperar da sua desordem: eu sempre embasbaquei em hum rei que me pareça hum homem, em hum ministro que me pareça hum rei, na rainha que me pareça mãe, no valido que não pareça escravo, no Grande que pareça filósofo, na Princeza que se pique de modesta, e no Heroi que se mostre menos galã que religioso. E querer que os Autores se não retratem nas suas obras, principalmente

\footnotetext{
${ }^{6}$ Sobre a utilização da oposição entre "mimesis icástica" e "mimesis fantástica", leia-se, antes de mais, Luzán, que a leu em Platão mas que a defende com argumentos aristotélicos (Luzán, 1977: 169 ss). Hernâni Cidade utilizará esta terminologia para designar, ao longo do século XVIII, a cada vez maior importância da verdade da História (e depois da Ciência, no século XIX) em detrimento da verdade do Mito (Cidade, 1984: II, 251 ss., max. 297-310).
} 
analisando costumes, e tratando da anatomia do coração humano, é querer impossíveis. (Figueiredo, 1804-1815: IX, 444) ${ }^{7}$

Não seria o único a dizê-lo no século XVIII. Parece ser essa a posição dominante, numa classe intelectual que, nascida e criada na corte e depois nas academias, ainda ávidas de protecção régia, evitava afrontar claramente o poder régio ou a hierarquia social. Significativamente, em 1830, a peça Hernani, de Victor Hugo, provocaria o público parisiense, ao mostrar o rei de Espanha temendo a chegada do marido da fiel Doña Sol, pedindo para ser escondido num armário (Hugo, 1971: 37, Hernani, I, 1). Falar sobre verosimilhança é sempre falar sobre uma expectativa de verdade aceitável, pessoal ou colectivamente. Ainda quando falamos de verdades científicas, é "verdade" aquilo que acreditamos ser verdade, o que a Ciência nos diz ser verdade, o que devemos pensar que deve ser a verdade. Com evidentes consequências em toda a estrutura da intriga, o discurso da Verdade confunde-se assim quase inelutavelmente com o discurso da Verosimilhança. $E$ o da Mentira com o da Inverosimilhança. O que nos sustém não passa, nas palavras de Greimas, de um Contrato de Veracidade/ Veridicção ("un Contrat de Véridiction"), ainda que tácito. Contrato leonino, no entanto, porque, na prática, se baseia numa imposta "visão da" realidade, e não "na" realidade. O "verosímil", o que se acredita ser verdade ou pode ser apresentado como tal, deriva desde logo de um pré-conceito de normalidade (a existência de uma regra da qual só podem, quando muito, extravasar excepções (Greimas, 1983: 103 ss.). Depois, e fruto desta ideia de normalidade, o verosímil é uma crença colectiva no que é normal, no que é regra, no que é a boa opinião e a opinião correcta, ortodoxa, sendo essa normalidade indissociável da experiência do grupo ou da comunidade: "l'orthodoxie succède à la croyance [...], une suite fatale de toute croyance qui réussit ou, en tout cas, elle [l'orthodoxie] est une tentation à laquelle peu de croyances résistent" (Grenier, 1938: 14). É raro o discurso político que apresenta a verdade como um conceito potencialmente relativo. O discurso da verdade dialéctica implica quase sempre uma sociedade que educa para o debate e para as nuances de sentido. Na ausência dessa cultura, ou frequentemente apesar dela, o que prevalece é uma marginalização do Indivíduo ou do grupo heterodoxos.

\footnotetext{
7 Atitude que veremos diferente em Garrett, que mais depressa lê Sófocles com o olhar de Eurípedes. Como há muito assinala Ofélia Paiva Monteiro: "Significativa nos parece ser para a avaliação da mundividência juvenil de Garrett a sedução exercida pela figura de Ifigénia, tão cara à ideologia e à sensibilidade predominantes no último quartel do século XVIII europeu. Lembremos só a tragédia de Gluck com libreto de Guillard (1779) e a tragédia de Goethe representada em Weimar em 1786, ambas inspiradas na Ifigénia em Tauride, geralmente preferida na época à Ifigénia em Aulide, cuja acção se prendia a motivações religiosas que a Aufklarung rejeitava" (Monteiro, 1971: I, 100). Figueiredo, nesse sentido, ao escolher traduzir Ifigénia em Aulide, aproxima-se de Garrett, ainda que o faça resistindo.
} 
Toda a ideia de inverosimilhança radica assim, de forma indirecta, na de ortodoxia, e a "ortodoxia" é, em sentido etimológico, a opinião pública "direita", a ossatura estrutural, ortopedicamente correcta. A "heterodoxia", pelo contrário, será a outra (hetero-) opinião, aquela opinião que extravasa a opinião da comunidade, esta sim dita a opinião comum (endoxa) e a boa opinião (eudoxa). Tendencialmente, o que reproduz o discurso da autoridade tem um discurso verosímil, e aquele que o põe em causa é, em certa medida, o traidor (aquele que, do ponto de vista retórico, fala de uma posição ingrata, sem ethos, sem poder contar com a empatia do grupo ${ }^{8}$ ). A concepção de "verosimilhança" resultaria, assim, de uma relação algo tirânica entre aqueles que detêm a codificação da linguagem e os que a discutem. Antes de ocorrer uma discussão, já se encontrariam pré-definidos os discursos permitidos e não-permitidos, compreensíveis e incompreensíveis, em suma: legíveis ou ilegíveis. Daí o interesse de Richelieu pelas academias reais do século XVII: a missão académica de elaborar um dicionário, uma gramática e uma retórica é uma tentativa do poder para encomendar aos intelectuais, promovendo-os, a lista das palavras que podem ser ditas e como devem ser escritas, bem como a forma como as ideias podem ser organizadas ou argumentadas (cf. Malato, 2009: 19-22). É porque estão afastadas dos centros de poder que, em França, ao longo do século XVIII, passam a ter mais espaço contestatário as academias de província e os domésticos salões literários.

Então como nos nossos dias, a conformidade do verosímil e inverosímil perpassa assim por quase todos os procedimentos de censura ou de resistência a essa censura. Pela credibilidade fácil do discurso da ortodoxia e pela desconfiança natural face à heterodoxia, suspeita de ruptura com uma comunidade. Porque a ortodoxia é invariavelmente totalitária, devoradora de discursos heterodoxos:

L'orthodoxie commence par les ignorer si elles lui sont contraires, par organiser le silence autour d'elles. Puis lorsque cela n'est plus possible, elle les attaque et tâche, par tous les moyens, de les supprimer. Enfin, devant leur résistance invincible, elle les adopte et les fait entrer dans son système. On finit par déclarer parfaitement compatibles avec les croyances primitives des connaissances qu'on a d'abord déclarées contradictoires, et à ce moment l'orthodoxie se change en éclectisme. Mais elle s'efforce de ne rien perdre de son autorité en prétendant qu'elle n'a rien cédé, alors qu'en réalité elle s'est modifiée. (Grenier, 1938: 17)

\footnotetext{
8 "A inteligência crítica é menos necessária para se ser bem sucedido: outras virtudes são requeridas doravante e o sentido do esforço deve ser reorientado. Resumindo, é como se, à força de sucumbir sob o peso das respostas educativas e mediáticas, nos esquecêssemos de questionar" (Meyer, 1998: 150).
} 
Mas, a nosso ver, daí se devem concluir também os artifícios contrários. Existe, sobretudo no discurso literário, uma provocação genética que convive desde sempre com o silêncio ou outras estratégias de sublimação do conflito. $O$ que acontece é que o discurso crítico sobre o século XVIII português nem sempre o detecta: não só porque o distanciamento temporal alimenta a insensibilidade perante os significados conotativos, mas também porque parece ser particularmente difícil na sociedade portuguesa a manutenção de uma cultura que eduque para o debate e para a amplitude do discurso crítico. $O$ intelectual prefere, talvez por isso, a formulação perifrástica ou elíptica que permite (na forma atenuada da ampliação, ou na forma condensada da máxima) ir ainda assim repetindo o proibido, ainda que de maneiras não preceituadas e não directas. Vitorino Nemésio, que tentou fazer um levantamento das polémicas exemplares na literatura portuguesa", afirma que o português se revê em Eurico, no bravo suicida, no louco, "ao parapeito" e "os seus sucessores na polémica civil e pessoal da literatura portuguesa não fizeram mais que carregar os traços e as cores de um tipo linguístico de combate por assim dizer congénito com o modo de ser nacional, que, em tensão pendular entre o lirismo e o sarcasmo, disfarça ou vela uma espécie de amor vital de ingenuidade humana." (Nemésio, 1964: x e xviii-xix). Para escapar a esta solidão (da loucura ou da clarividência) resta quase sempre à heterodoxia a possibilidade de se disfarçar. Preferencialmente disfarçando-se de ortodoxia. Na verdade, como cremos que se pode demonstrar com a obra de Manuel de Figueiredo, poderíamos inverter a frase de Grenier, aplicando-a agora à heterodoxia. Também ela "s'efforce de ne rien perdre de son autorité en prétendant qu'elle n'a rien cédé, alors qu'en réalité elle s'est modifiée”.

Percebemos talvez melhor a posição charneira de Manuel de Figueiredo se lermos as cartas que trocou com Isidoro Soares de Ataíde sobre a querela do Cid, de Corneille. Não podemos afastar os vários pontos tratados nas cartas (a definição do Belo, a utilidade da Crítica, a polémica sobre a inverosimilhança em França e, cem anos depois, em Portugal...) do ecletismo setecentista, que visa conciliar os pressupostos racionalistas e os empiristas ${ }^{9}$. Voltamos à falsa bipolarização entre "Belo ideal" e "Belo ponderado", elaborada ao longo do século XVII sobre a poética de Aristóteles. Por um lado, a universalidade do Belo (e da Verdade), somente apreensível pelo uso da razão, faculdade distribuída de igual forma a todos os homens. Por outro, a particularidade da opinião, dependente que esta se encontra das diferentes experiências com o sensível, em cada sociedade e em cada indivíduo. Escreve Isidoro Soares de Ataíde, mais fiel ao racionalismo estético, mas colocando timidamente as suas dúvidas a Figueiredo:

\footnotetext{
${ }^{9}$ Cf. J. S. da Silva DIAS, O ecletismo em Portugal no século XVIII. Génese e destino de uma atitude filosófica, in "Revista Portuguesa de Pedagogia", Coimbra, Ano VI, 1972.
} 
Eu não estou bem com aqueles que afirmam que cada nação tem seu teatro particular: porque se a arte regulou o drama, a mesma arte que se pratica em uma nação se deve observar em outra. A arte é filha da razão e a razão em toda a parte deve dominar. (Ataíde apud Figueiredo, 1804-1815: XII, 531)

Responde-Ihe todavia Manuel de Figueiredo, mitigando-Ihe o racionalismo com os argumentos empiristas, falando-lhe já das diferenças entre as línguas como sinal das diferenças de "génio da Nação":

He livre, impio, e satyrico o Inglez; é bufão, e velhaco o Italiano, louco e sensível o Hespanhol; o Francez critico e "sans façon"; o Latino ama a natureza e a Verdade; o Grego he republicano. (Figueiredo, 1804-1815: XII, 540)

Não deixa de ser curioso que o faça recorrendo ainda ao conceito aristotélico da Poesia como Imitação, e combinando-a com uma leve sugestão da teoria climática do Belo, que bem podia ter lido, directa ou indirectamente, no L'Esprit des Lois, de Montesquieu, onde se procura demonstrar a influência do próprio clima nos governos e nas religiões:

\begin{abstract}
A natureza, a verdade e a razão é de todas as nações e de todos os tempos; porém, como a Poesia é imitação, a diferença dos costumes, a liberdade de linguagem, génio da Nação, e ainda os governos e as religiões, influem tanto naqueles Poemas cómicos, e o mesmo clima (que influi em tudo), que por isso, sem tocarmos nas regras, distinguimos os teatros. (Ibidem)
\end{abstract}

E Manuel de Figueiredo remata a síntese, referindo a limitação de algumas regras poéticas que, como crítico, racionalmente defendia. Pois parece acabar por descobrir em si duas personalidades distintas, com diferentes critérios de decisão, e duas retóricas opostas: a de crítico, racional, e a de espectador, emotivo. Quantas vezes sucedera, quando ia aos teatros, esquecer-se da razão em casa? Ria então "de qualquer género de bufonada"! Sóbrio académico, desmanchava-se "como um galego de saco ou um preto meio buçal" (Ibid: 544-545). Admira Sófocles, mas não deixa de se sentir devedor das gargalhadas que deu ao ver representadas as Óperas de Bonecos, de António José da Silva ${ }^{10}$ ou os

\footnotetext{
10 "Esquecia-me fallar nas Operas de bonecos, com as quaes devemos ser mais indulgentes que com outras nenhumas composições dramáticas, perdoe-me o nosso eruditissimo Candido Lusitano; para animar huns bocados de cortiça (satisfação que dá no seu Prologo o engenhoso, e graciosíssimo António José) he necessário compor no gosto em que elle o fez, e valer de toda a extensão do nosso discreto dito. A gente não se ri senão de asneiras. Olhem que o ouço ainda a boa gente: boa gente, explico-me, segundo o nosso modo de fallar." (Figueiredo, 1804-1815: VIII, xlvi).
} 
equívocos dos Arlequins da Commedia dell'arte ${ }^{11}$. E recuperando talvez o argumento de Aristóteles em defesa de Eurípedes, ou lembrando-se dos preceitos que Lope de Vega fechava à chave enquanto escrevia, conclui:

Eu pela graça de Deus, sei o Evangelho: mas pinto os homens como são. (Figueiredo, 1804-1815: VIII, xlvi).

Não podemos deixar de nos perguntar se houve, na escrita de Figueiredo, um progressivo abandono do racionalismo filosófico e da universalidade do conceito de "beleza ideal" que the está associada. As cartas entre Manuel de Figueiredo e Isidoro Soares de Ataíde não são datadas. Pelas referências, podem pelo menos datar-se do final dos anos 70. Mas as sementes estavam na sua obra, talvez desde os tempos em que escrevia para a Arcádia e lia em Aristóteles sobre a eficácia do inverosímil. Ou quando as procurava encontrar na eficácia dramática das peças de Shakespeare ou de Corneille:

Não vos oprimais, Espíritos grandes, com a multiplicidade de regras, buscai o fim, movei as paixões: mais estimo uma cena dos monstruosos dramas de Shakespear [sic] do que os regulares poemas de ${ }^{* * * *}$. (Figueiredo, 1804-1815: I, 171)

Por fortuna não houve outro Corneille, senão lá ia a Poética de Aristóteles. (Figueiredo, 1804-1815, XII, 112)

Não chegou a traduzir Shakespeare. Mas obcecava-o Corneille, de que traduziu Cinna e Le Cid. Obcecava-o sobretudo Le Cid:

O Cid de Corneille é tão admirável como o Édipo de Sófocles. Chefes são estes dois únicos homens, das duas seitas totalmente opostas. [...] A admiração e as lágrimas, se acaso não são o fim trágico, são o meio de o obter. [...] O Cid de Corneille é tão monstruoso como grande. Tira sem comparação mais lágrimas que o Édipo de Sófocles. (Figueiredo, 1804-1815, VIII, xV-xvi)

O Cid é um poema de acção irregular, desde logo porque the deu o ser Guillén de Castro, autor valenciano da escola de Lope de Vega, que assim classificou Las Mocedades del Cid. Mas também porque assim os críticos a reputaram e baptizaram, quando imitada por Corneille. O Cid deu origem a uma querela em França no século XVII e a outra em

\footnotetext{
11 "O Arlequim no teatro a ninguém faz rir tanto como a mim, e ainda fora de cena, confesso a verdade, me agrada" (Figueiredo, 1804-1815: IX, 209).
} 
Portugal, no século XVIII, a crer em Manuel de Figueiredo (cf. Pimpão, 1962: 259-273). Mas O Cid de Corneille permanece para Manuel de Figueiredo um monstro, ainda quando circula sob o falso rótulo de "Poema Regular", talvez por se associar agora, não sem paradoxo, ao gosto francês, dito "clássico". Figueiredo ri-se da estratégia da ortodoxia: para que Le Cid pudesse pacificamente apresentar-se como exemplo clássico dos críticos setecentistas, a ortodoxia mudava-Ihe o rótulo, escamoteava-Ihe as diferenças, limpava-a da novidade: "aparece com o mesmo rótulo de monstro, tragicomédia: depois he que o crismaram com o título de Poema Regular com que hoje corre" (Figueiredo, 1804-1815: XII, x). Há até uma auto-ironia nas palavras de Manuel de Figueiredo. Lemos talvez muito mal se não a lemos:

\begin{abstract}
Eu procedo debaixo dos mesmos absurdos do Critico e dos Juizes (porque ainda não achei as regras da tragicomédia que elles dão a entender que sabem, procedo debaixo dos mesmos absurdos, criticando um monstro pelas leis dos Poemas Regulares; e notando, no Cid de Corneille, os defeitos de D. G. de Castro. (Figueiredo, 1804-1815: VIII, xviii)
\end{abstract}

Auto-ironia que desde logo implica uma dilatada observação das fontes críticas.

vendo quão inutilmente me havia cançado em imitar Sophocles, e Molière (pois era tão simples que unicamente o queria fazer no que elles são inimitáveis) entrei no appetite de crear também o meu monstrozinho (Figueiredo, 1804-1815: V, i-ii)

"O meu monstrosinho", assim denomina carinhosamente a sua "Grifaria", escrita certamente nos finais da década de 70 , por nem ele a conseguir enquadrar na realidade conhecida e ela se assemelhar assim aos monstros que cada vez mais admira. Assume-se aqui a solidão do seu pensamento, mas também um não disfarçado orgulho na Inverosimilhança imanente: nas "Extravagâncias", na "Imaginação doente e agitada". Em "A Grifaria", talvez pressentindo a estranheza do argumento, aparentemente alheio às autoridades de Aristóteles ou Horácio, Manuel de Figueiredo justifica-se também, com o velho argumento retórico do "Sonho". O Epíteto da peça, antecipando os crimes da falta de qualquer regra da unidade de tempo ou de lugar, começa por escrever: "Não sei se li ou se sonhei que...." (Figueiredo, 1804-1815: V, s.p., "A Grifaria”, Epiteto). O sonho é um conhecido elemento de validação e creditação do insólito, ainda e sobretudo num século XVIII marcado pela aversão ao elemento da Superstição (Costa, 2005: passim). É porém espantosa esta possível sinonímia proposta entre o acto de leitura e o estado onírico, designando um estado de criação inconsciente que aproxima a Leitura ("não sei se li”...) do Sonho (..."ou se sonhei"), fazendo lembrar (ainda que absurdamente) o preceito surrealista 
do poeta Saint-Paul Roux, colocado na porta do quarto de dormir: "Le poète travaille". Mas parece-nos legível esta "monstruosidade" estética que se apresenta como similar a um estado inconsciente, em que a razão se encontra adormecida. Por isso parece doentio o estado em que escreve: "Esquenta-se-me o cérebro...de sorte, e tal o entusiasmo se senhoreou de mim, que não só deitei por esses ares, mas, cansado já de andar pelo espaço imaginário, fixei a imaginação no Mundo da Lua" (Figueiredo, 1804-1815: V, s.p., "A Grifaria", Epiteto).

Num discurso escrito também depois de 1776, referindo-se a um único confidente, dilo testemunha da sua transformação como sujeito perante um real aparentemente imutável. Recordamos com Figueiredo, os deslumbramentos contínuos perante o mesmo objecto, seja ele uma paisagem social ou um texto literário...

Em fim, as extravagancias e fatuidades que me passão pela imaginação doente e agitada, todas the ponho patentes, todas servem para reflectirmos e acabarmos de conhecer quanto de instante para instante he o homem differente de si mesmo, ou totalmente outro homem. (Figueiredo, 1804-1810: II, 175-6)

O prefácio que redige, quinze anos mais tarde, para a tragédia Osmia, logo arrumado na gaveta, evidencia ainda mais a liberdade com que ele próprio se comenta, tomando agora por confidente o papel, o mais discreto dos secretários:

Rompo a cena com hum enigma, e fecho-a, ensanguentando o theatro. Que crimes! E agrada-me! (Figueiredo, 1804-1815: II, 349)

E todavia, o autor parece não se dar conta (ou melhor, parece não nos dar conta) de uma evolução significativa ou de um dilema conceptual, já que a fonte de toda a sua arte permanece sempre a "verdade útil", e é unicamente no seu fito que se serve da autoridade canonizada (do que é velho ou chega do estrangeiro). Leu os autores da Antiguidade e tudo o que Ihe podia chegar de Itália ou França: "Leio os drammas que aqui nos chegão, todos os de Itália, e ainda os de França" (Figueiredo, 1804-1815: IX, 219). E a tal ponto o faz, que a língua francesa contamina a pureza da língua materna, estraga-lhe a boa gramática e o dicionário (Figueiredo, 1804-1815: II, 349). Estraga-lhe também a retórica com que o esperavam bem ensinado.

É puxando o metódico fio de Ariana que ele, qual Teseu perseguidor de imprevisíveis Minotauros, se descobre no meio de um labirinto da verdade, que é simultaneamente metódico e imprevisível, feito de verosimilhança e de inverosimilhança: 
Agora porem he que eu conheço o labyrintho em que me meti. Eu quero escrever dramas uteis e verosimeis. Onde está o poeta que hei-de imitar, onde os originaes que hei-de seguir? Hei-de mover o riso, o riso critico. E onde encontrarei os caracteres? (Figueiredo, 1804-1815: I, v)

Do ponto de vista da autorizada e verosímil poética dos géneros, "A Grifaria" é um grifo, um ser híbrido, composta por partes de animais diferentes que se movem grotescamente como um todo harmónico (Figueiredo, 1804b: V, s.p., "A Grifaria”, Epiteto). Devia ecoar na sua memória a crítica sibilina de Horácio, como se ela fosse dirigida aos seus "sonhos de enfermo":

Creiam-me Pisões, bem parecido com um quadro assim seria um livro onde se fantasiassem formas sem consistência, quais sonhos de enfermo, de maneira que 0 pé e a cabeça não se combinassem num ser uno." (Horácio, 1985: 55)

Voltar para trás, para uma estética uniforme, é-lhe todavia impossível. No Discurso de "Osmia", logo em 1773, antecipa a crítica que Ihe farão ao "estilo difuso" por que se explicava no Drama: "mas saiba-se também que não foi desmazelo, foi sim gosto" (Figueiredo, 1804-1815: II, 349).

O Teatro do Mundo lá fora irrompe pelo Mundo do Teatro, desprezando a imitação de rituais, porque a imitação, como rotina e regularidade, desde logo quando impede o deslumbramento, se pode revelar uma antecâmara da morte. Morte do Teatro, mas também morte do Mundo que ele iluminava. Não é certamente por acaso que Manuel de Figueiredo termina o Discurso sobre O Cid, exortando os críticos a suspender as suas críticas a géneros como a Tragicomédia ou a Ópera:

Acabei o Discurso, que era o meu caso, e cerra-lo-ei pedindo por caridade aos meus Patricios que se não mettão a criticar seriamente Tragicomedias, Operas, nem das chamadas Tragicas, nem Comicas, Farças, Burletas, Entremezes, Sainetes, Divertimenti in Musica, Serenatas, Loas e cousas deste género: e creião-me, porque as Regras de semelhantes composições não estão em Aristóteles, nem em Horacio: estão no Theatro, na Musica e no Povo; e no verniz que Ihes dá um ou outro Comico. (Figueiredo, 1805b: VIII, xIv) 


\section{Conclusão: por uma dramaturgia inverosímil}

É difícil, e prematuro, elaborar de tudo isto uma conclusão inequívoca. Não é possível fazer de Manuel de Figueiredo um romântico verosímil, nem sequer um préromântico convincente, e sem dúvida o evitámos até fazer. Demasiado romântico para ser arcádico. Demasiado arcádico para ser romântico. A historiografia portuguesa não chegou a fazer uma revisitação da sua periodologia como a que foi proposta, na historiografia francesa, por Emile Deschanel, autor de Le Romantisme des Classiques (1883-1886) ou por Pierre Moreau, autor de Le Classicisme des Romantiques (1932). Ou quando tardiamente a esboçou foi para recuperar conotativamente a ideia de Romantismo ou de Classicismo. Mas Figueiredo parece ainda hoje também, neste rígido contexto português, demasiado associado à teoria poética para ser considerado enquanto dramaturgo. Ou dramaturgo demasiado difuso para ser bom teórico. "O que he o mundo!": pois tendo ele começado um caminho com muitos o acabou sozinho, ou com a ideia de que o estava. Também o facto de ninguém o ter visto representado e poucos o lerem vem ajudar a que essa solidão se julgue inabilidade do próprio sujeito e não característica do seu objecto. Tendo Manuel de Figueiredo levado à cena uma única peça (Os Perigos da Educação), e durante pouco mais do que uma noite fatídica (a de 8 de Maio de 1774), os seus delatores podem reproduzir com facilidade uma velha explicação da crítica para os fracassos de bilheteira: a preocupação poética matou-lhe a dramaturgia, a literatura destroçou-lhe o teatro, a preocupação de verosimilhança tornou-o inverosímil, quer para o seu público, quer para o actual.

Mas as inabilidades do autor não nos dispensam a nós, historiadores da literatura, de regressar ao local do crime. Bem pelo contrário. Sobretudo quando suspeitamos de algumas pistas $^{12}$. Devemos regressar aos textos e aos géneros, despreocupadamente e de vez em quando, suspeitando da sua poética "verosímil"... Pelo menos tanto quanto abertamente negligenciámos a dita "inverosímil"! No dizer sempre abalizado de Sherlock Holmes, "as coisas mais estranhas e esquisitas geralmente têm relação não com os maiores crimes, mas com os menores", e ocasionalmente, há mesmo razão para duvidar se houve crime ou não (Doyle, 2009: 8).

Cremos que, quando o fizermos sem ligar a lugares-comuns e consabidos, estranharemos a atenção que Manuel de Figueiredo deu, não só à poética, como à dramaturgia. Descobrimo-lo-emos então frequentador muito assíduo de teatros e um

\footnotetext{
12 A versificação imperfeita, o ritmo inapropriado, o vocabulário desconcertante, a intriga mal construída, as personagens extensamente didácticas, nunca impediram verdadeiramente as edições ou as representações. Também Mlle. Ricobonni criticava a Diderot o facto de escrever as suas peças não no palco mas no espírito (apud Dieckmann, 1959: 30).
} 
dramaturgo complexo, experimentalista, até inovador. Muitas vezes contrariando a teoria com a prática. Ainda que de uma forma quase sempre ambivalente e pouco sistemática. Quantas “contradições", ou "meios-termos", pois o rótulo dependerá do nosso ponto de vista! Temendo o público sequioso de sangue em palco, Figueiredo ria-se dos que para não sujar o palco, matavam com veneno (Figueiredo, 1804-1815: XI, 137). Não achando dignas do palco meiguices de homens barbados, fez do amor o tema da maior parte das suas tragédias. Receando o poder da música sobre o entendimento dos espectadores, afirma aceitar de bom grado a música se se restituíssem os Coros, como aliás tentará Schiller (Figueiredo, 1804-1815: IX, 443, cf. Schiller, 1997: 233-239). Não se babando por música, escreve um sainete, porque "nós necessitamos de introduzir o bom gosto neste povo bárbaro com as precauções com que o Apóstolo foi introduzindo o Cristianismo nos Gentios" (Figueiredo, 1804-1815: XII, xi)... Pressupõe-se assim que, como S. Paulo, Manuel de Figueiredo nunca fez questão em que todos os iniciados fossem poeticamente circuncidados.

Devia, por exemplo, dedicar-se um estudo mais pormenorizado ao cuidado que Manuel de Figueiredo tem com as didascálias. Até porque parece ser raro na época um autor com estas preocupações de dramaturgo, sobretudo quase não tendo obra representada. E a sua prática parece contrariar a informação de Anne Surgers, ou fazer de Figueiredo um pioneiro, antecipando-se a Beaumarchais: "Com As Vodas de Figaro (17811784), por primeira vez, o teatro dramático inclue descricións de traxes, decorados e desprazamentos dos personaxes" (Surgers, 2009: 210). Na última fase da produção de Manuel de Figueiredo, entre 1773 e 1777, as didascálias parecem aumentar em quantidade e qualidade. São bastante frequentes as indicações sobre o vestuário, os adereços. Especificam-se as entoações anormais que devem usar os actores:

Sala rodeada de estantes, com livros de differentes tamanhos, papeleira, tamborete, bofete com duas velas acesas. Livros pelo chão, por cima dos tamboretes, e sobre a mesa. Porta que comunica com outro quarto, com fecho, etc. O bofete estará no meio da casa e huma cadeira ao pé della. (Figueiredo, 1804-1815, IV, s.p., "Poeta em annos...", I, 1)

São importantes também os ruídos: as portas devem bater, as campainhas devem ouvir-se, os actores devem passar a ter vozes assustadas, ou a pronunciar palavras sussurradas... Peças como a comédia Alberto Virola aproximam-se até do melodrama oitocentista: há cenas que nos parecem bem concebidas, a ser representadas na escuridão, com lanterna, facadas, gritos... 
É curioso! Neste autor de dramas que escreve para a gaveta, as didascálias tomam por vezes a forma de recomendação metafórica, por se sentir limitada a referência denotativa.

Uma personagem deve falar "em ar de tocar-lhe o fogo"!

Em anos de prosa, a criada, furiosa com o Poeta, "varre a casa por parágrafos"!

Na continuidade das reflexões de Diderot sobre a importância da representação ${ }^{13}$, ou tão somente recordando-se das reflexões de Correia Garção sobre o Sublime apresentadas, em 1755, à Academia dos Ocultos, e decalcadas em parte de Boileau ${ }^{14}$, Manuel de Figueiredo parece reforçar, ao longo dos anos, a importância dos silêncios e dos gestos:

Esta é a terceira vez que deixo o teatro em silêncio neste Drama; e como cai no mesmo defeito em outros por sacrifício à Verosimilhança (...) devo advertir os Cómicos de que, nestes momentos, não só afeitem a pantomima e a carreguem, como dizem os italianos, quanto o permitir o Carácter das personagens e a paixão. (Figueiredo, s.d.: s.p.)

Talvez a Inverosimilhança seja a única estética possível. Ainda quando se apresenta sob o nome de Verosimilhança. Ainda quando o que se busca leva ao seu contrário. Ou o resultado se esvai em inabilidades. "De resto, não será mesmo muitas vezes ao falhar no seu projecto que uma obra literária chega a ser bem sucedida? A literatura, ao expressar a excepção, proporciona um conhecimento diferente do conhecimento erudito, mas mais capaz de elucidar os comportamentos e as motivações humanas" (Compagnon, 2010: 48). Porque o Estranhamento é inegável meio da Literatura e do Teatro. Porque toda a Dramaturgia pode, perante a "passividade" do espaço literário, sugerir um "a-topos", e pôr literalmente em cena um "fora do sítio" que permita ao espectador sair do seu sítio, do seu sentido, parcial e acomodado: "visando a superação dos efeitos de ilusão, ficção e denegação, visa transformar o ouvinte passivo num espectador crítico" (Barata, 2001:33).

Como poderia ser de outra maneira? No Mundo do Teatro, a verosimilhança é tão falsa quanto a inverosimilhança. E sendo defeito deve certamente afeitar-se e carregar-se. Até o defeito se transformar em Arte. Porque no Teatro do Mundo, só a imperfeição é natural.

\footnotetext{
13 "La pantomime si négligée parmi nous, est employée dans cette scène; et vous avez éprouvé vous-même avec quel succès! Nous parlons trop dans nos drames; et conséquemment, nos acteurs n'y jouent pas assez." (Diderot, 1975: 126).

${ }^{4}$ Correia Garção, "O que he o sublime", in Melodrama, Coimbra, presentemente no prelo.
} 


\section{Bibliografia}

AA. VV. (1964). As grandes polémicas portuguesas, pref. V. Nemésio. Lisboa: Ed. Verbo.

AGUADO, Emiliano (1942). El Arte como Revelación. Madrid: Espasa-Calpe.

ARISTÓtelES (1986). Poética, ed. Eudoro de Sousa. Lisboa: IN-CM.

BARATA, José Oliveira (2001). O Espaço Literário do Teatro. Estudos sobre Literatura Dramática Portuguesa I. Coruña: Univ. Coruña/ Biblioteca-Arquivo Teatral F. Pillado Mayor.

BAUdelaIRE (1979). Les Fleurs du Mal et Autres Poèmes. Paris: Garnier-Flammarion.

BorRALHo, Maria Luísa Malato (1985). Diderot e a Estética Teatral no Século XVIII Português. A Singularidade dos Dramas de Manuel de Figueiredo, in "Confluências", n.ำ 1, Coimbra, IEF/FLUC e Alliance Française, pp. 104- 114.

BorRalHo, Maria Luísa Malato. (1995). Manuel de Figueiredo. Uma perspectiva do Neoclassicismo Português (1745-1777). Lisboa: IN-CM.

BorRALHo, Maria Luísa Malato (2004). A Retórica do Silêncio na Literatura Setecentista, In "Revista da Faculdade de Letras da Universidade do Porto". Série II: Línguas e Literaturas. In honorem Doutor Jorge Osório e Doutor Joaquim da Fonseca". n. XX, t. I, pp. 145-169.

CIDADE, Hernâni (1984). Lições de Cultura e Literatura Portuguesas. Vol. II: Da Reacção contra o Formalismo ..., 2..$^{a}$ ed. Coimbra: Coimbra Editora.

Compagnon, Antoine (2010). Para que serve a Literatura? trad. José Domingues de Almeida. Porto: Deriva.

CoRneIlle (1976). Le Cid, ed. Yves Brunsvick, Paul Ginestier. Paris: Didier.

CostA, Carlos M. F. Brejo da (1967). Manuel de Figueiredo, preceptista e autor dramático português do século XVIII, Dissertação de Licenciatura. Lisboa: FLUL.

COSTA, Leila de Aguiar (2004). O Abade, o Presidente e o Cavaleiro: a disputatio em Charles Perrault, in "A Constituição da Tradição clássica", org. Luiz Marques. São Paulo: Hedra, pp. 233-255

CostA, Palmira Fontes da (2005). O corpo Insólito. Porto: Porto Editora.

DiECKMANN, Herbert (1959). Cinq Leçons sur Diderot. Genève/ Paris: Droz/ Minard.

DOYLE, Sir Arthur Conan (2009). A Liga dos Cabeça Vermelha. Lisboa: Global Notícias.

FIGUEIREDO, Manuel de (1804-1810). Obras Posthumas, 2 vols., Lisboa: Imp. Regia.

FIGUEIREDO, Manuel de (1804-1815). Theatro, 14 vols. Lisboa: Impressão Regia.

FIGUeIREDO, s.d. Poezias e outros textos. BNL. COD 12925, Mss. 8.ำ, folha solta.

GARÇÃo, Correia [2011?]. O que é o Sublime, "Melodrama". Coimbra, no prelo.

GARRETt, Almeida, s.d. Obras de..., 2 vols. Porto: Lello \& Irmão.

GreimAS, Algirdas Julien (1983). Du Sens II. Essais Sémiotiques. Paris: Ed. du Seuil.

GRENIER, Jean (1938). Essai sur l'Esprit d'Orthodoxie. Paris: Gallimard.

HoRÁcıo (1985). Arte Poética, in "A Poética Clássica", trad. Jaime Bruna. S. Paulo: Cultrix.

Joly, Morwena (2009). Le Modèle Antique examine sous l'angle anatomique: entre Beau idéal et Beau réel (1670-1812). In "Dix-Huitième Siècle. Individus et Communautés", n.ำ41, Paris: La Découverte/ SEDS.

LUZÁn, Ignacio de (1977). La Poética. Reglas de la Poesia en general y de sus principales espécies. Barcelona: Editorial Labor.

MALATO [Borralho], Maria Luísa/ Destain, Christian/ PARMENTIER, Isabelle (2009). Le XVIIle Siècle. Une Epoque d'Ombres et de Lumières, ed. Anne Staquet. Mons: Ed. I'UMons.

MEYER, Michel (1998). Questões de Retórica: linguagem, razão e sedução, trad. António Hall. Lisboa: Edições 70. 
MONTEIRO, Ofélia Malheiro C. Paiva (1971). A Formação de Almeida Garrett, 2 vols. Coimbra: Centro de Estudos Românicos.

PIMPÃo, A. J. da Costa (1962). La Querelle du Théâtre Espagnol et du Théâtre Français, in "Revista de História Literária de Portugal", n.ำ 1, Coimbra, FLUC, pp. 259-273.

SCHILLER, Friedrich (1997). Textos sobre o Belo, o Sublime e o Trágico, ed. Teresa Rodrigues Cadete. Lisboa: IN-CM.

SURGERS, Anne (2009). Teatro Occidental: Unha Historia Teatral desde a Escenografía, trad. I. López Silva. Vigo: Xunta de Galicia.

VeRnEY, Luís António (1991). Verdadeiro Método de Estudar. Cartas sobre Retórica e Poética, ed., introdução e notas de Maria Lucília Gonçalves Pires. Lisboa: Editorial Presença. 